\title{
EXPLOITING KNOWLEDGE FLOWS: OPENNESS AND THE INNOVATIVE PERFORMANCE OF BUSINESS SERVICES
}

\author{
ANDREA MINA \\ University of Cambridge \\ Cambridge Judge Business School and CBR, \\ Trumpington Street, CB21AG, Cambridge UK. \\ ELIF BASCAVUSOGLU-MOREAU \\ CBR University of Cambridge
}

ALAN HUGHES

CBR University of Cambridge

\section{INTRODUCTION}

Innovation requires a capacity to seek, absorb and utilize external knowledge, and an ability to develop, leverage or exchange internally-generated knowledge. While the exchange of knowledge among agents is partly an emergent property of networks, from the viewpoint of the firm this requires substantial organizational efforts (Foss, 2005). A growing emphasis on the notion of open innovation (Chesbrough, 2003; 2006) has popularized important aspects of the problem of the external organization of the firm. While the role of external 'openness' and its impact on firms' innovation performance have been studied in prior literature, the role of 'internal openness' in this context has received less attention (Love et al. 2011). And yet, the opening up of innovation processes poses a distinctive set of challenges for the overall organization of knowledge flows (Colombo, Laursen, Magnusson, and Rossi-Lamastra, 2011; Foss, Laursen and Pedersen, 2011).

Firms differ both in the intensity of use of knowledge exchanges across and within organizational boundaries. Moreover, firms have different preferences for the mechanisms through which these exchanges can take place. These can be formal or informal. This paper explores the impact on the innovative performance of firms of 1) external and internal openness, 2) the interaction between external and internal openness, and 3) formal vs. informal activities.

Our empirical focus is on business services, a low capital-intensive sector of the economy that relies precisely on the organization of knowledge flows within and across boundaries to gain and sustain competitive advantage (Bessant and Rush, 1995; Hargadon and Sutton, 1997; Howells, 2006). The data we use are drawn from an original survey specifically designed and launched in 2010 to study the open innovation practices of UK companies. We first distinguish between the performance effect of internal knowledge flows and external ones. Our analyses reveal strongly significant and positive effects for both. When we distinguish between formal and informal mechanisms of access to external knowledge, we find striking differences: the former exert no noticeable effect on the innovative performance while the latter exert strong positive effects. Interestingly, pursuing both informal and formal practices seem to decrease the share of innovative sales, which can be interpreted as an indication of diseconomies of scale or managerial attention constraints. Finally, these effects appear to vary substantially across size classes. 


\section{THEORY AND HYPOTHESES}

\section{External knowledge flows and internal openness}

The ability to absorb external knowledge has been theorized as a significant driver of innovatiion (Cohen and Levinthal, 1990). Access to and use of external knowledge can enable firms to de-risk technology development and thus reduce technological uncertainty. They can allow firms to share costs, gain complementary assets, enter new markets, and realize economies of scale and scope in research (Ahuja, 2000; Cassiman and Veugelers, 2002; de Faria et al., 2010; Miotti and Schwald, 2003). But they also involve risks. These include the possibility that firms misdirect or misalign resources (Ahuja and Kattila, 2001; Sapienza, Parhankangas and Autio, 2004), that they exceed optimal levels of 'openness' and overstretch limited resources, including managerial attention (Ocasio, 1997), thus actually decreasing innovative performance (Laursen and Salter, 2006). While controlling for non-linear effects, we hypothesize that:

HP1: External knowledge flows exert a positive effect on firm' innovative performance.

The internal organization of knowledge is a major source of competitive advantage and one of the most important areas of strategic decision-making (Kogut and Zander, 1992; Nonaka, 1994). The sharing of knowledge has been found to exert a positive influence, for example, on team performance (Reagans and Zuckerman, 2001; Rulke and Galaskiewicz, 2000; Sparrowe et al., 2001) and has been related to the successful management of complex products that require a high degree of knowledge integration (Baldwin and Clark, 2000). Defined as the ability of firms to share and distribute knowledge within its organizational boundaries, internal openness reflects the organizational design of the firm and depends on its hierarchical structure, degree of cooperation among employees and informality of communication patterns (Bunderson and Boumgarden, 2010). Although there is a risk that excessive knowledge sharing reduces cognitive variety and thus limits the creative potential of the firm (Burt, 1992; McFadyen and Cannella, 2004), we posit that, by aligning objectives, creating a shared vision of tasks and responsibilities, and facilitating problem solving:

HP2: Internal openness exerts a positive effect on firm' innovative performance.

It can be argued that external knowledge flows and the internal openness of the firm induce synergetic effects on the firm's innovation performance: the full value of the knowledge that is brought into the firm from the external environment can be best exploited when it is shared and fully understood in different parts of the organization. The benefit of internal openness should more than compensate for the risk that a high frequency of internal cooperation, leading to an inward-looking organization, reduces the propensity to accept external knowledge inputs (Burt, 1992; Ibarra, 1992; Oh et al., 2004; Bunderson and Boumgarden, 2010). We therefore test for positive interaction effects and hypothesize that:

HP3: Internal openness enhances the effects of external knowledge flows on innovative performance.

\section{Formal and Informal Knowledge Flows}

Although the vast majority of existing contributions on firms' external search has focused on formal arrangements, a great deal of information exchange is in fact informal. Informal 
exchanges are difficult to capture because they typically leave no paper trail (Hagedoorn et al., 2000). Evidence, however, exists that firms often prefer informal to formal cooperative arrangements (Faulkner and Senker, 1995; Harabi, 1998; Bonte and Keilbach 2005). Work on industry-university linkages has shown that the highest proportion of the knowledge that is 'transferred' through informal links has tacit nature (Faulkner and Senker, 1995). In addition, the unplanned nature of informal interactions may be conducive to future successful collaborations (Kreiner and Schultz, 1993), although collaboration in informal innovation networks is typically not aimed at short-term innovation but rather at technology exchange, learning and the generation and testing of new ideas (Van Aken and Weggement, 2000). On these premises, we hypothesize that:

HP4: Informal activities will have a higher positive impact on firm's innovative performance relative to formal activities.

Beyond the direct effect of informal activities on innovation, informal searches may also increase the firms' performance indirectly by leading to more formal types of collaborative agreements (Kreiner and Schultz, 1993). As observed by Freeman: "Behind every formal network, giving it the breadth of life, are usually various informal networks" (Freeman, 1991: 503). Informal search activities can not only act as a catalyst for more formal collaborations, but can also ensure the latter's success. They help to overcome internal barriers and resistance to external knowledge as manifested through the so-called not-invented-here and/or not-sold-here syndromes (Katz and Allen, 1982). We therefore expect that:

HP5: Informal search activities will strengthen the relationship between formal external search and innovative performance.

\section{DATA AND VARIABLES}

\section{Empirical Setting}

The empirical setting of this study is the business services sector. This provides an ideal context for an analysis of knowledge flows from an innovation perspective given its intangible sources of competitive advantage and its high rates of innovation. Business services are intensive users of external knowledge sources (Hipp, 2010; Tether and Tajar, 2008) with high frequency of interaction with customers and suppliers (Tether, 2005; Leiponen, 2005). The 'relational' nature of service businesses makes them highly suitable to the adoption of 'open' innovation strategies. The relevance of the open innovation model for service businesses has recently been brought to the fore (Chesbrough, 2011). However, the availability of evidence on the effects of knowledge sourcing on the performance of business services is seriously limited by the fact that only the sources, but not the types, of knowledge exchanges have been captured in empirical research based, for example, on Innovation Survey data, which also do not include information on the internal organization of knowledge (Mansury and Love, 2008; Love et al., 2010).

\section{Data and Variables}

Data: The data for this analysis are drawn from the UK IRC Open Innovation Survey, specifically designed to study the open innovation practices of UK companies. The sample of business services firms has 442 observations but missing value problems reduce the size of the 
sample to 265 firms with complete responses. Between the original sample and our final database we do not find any sample attrition bias in our key variables, although there is an indication of a bias towards more knowledge intensive firms and results should be interpreted bearing this in mind.

Dependent Variable: Our dependent variable is the firm's innovative performance. The survey asked about the firms' total sales revenue in the last financial year derived from new and/or significantly improved products and/or services introduced within the last three years. This widely used measure of innovative performance reflects both the companies' ability to introduce new products as well as these latter's commercial success (Laursen and Salter, 2006; Leiponen and Helfat, 2011; Love, Roper and Vahter, 2011).

Independent Variables: The key explanatory variables in our study are firms' external knowledge flows and its internal openness. Internal openness is measured on a scale of items related to the role of co-operation, flat hierarchies and informal management styles, on a Likertscale of 1 to 5. Firms were also asked to indicate the degree of importance of a number of informal and/or formal activities with external parties for the purposes of innovation. Both measures are normalized sums of the amount of relevant dimensions/activities and have a high degree of internal consistency (Cronbach's alpha $=0.69$ and 0.84 respectively). Two additional measures of external knowledge flows have been constructed, by distinguishing between informal (Cronbach's alpha $=0.70)$ and formal (Cronbach's alpha $=0.82$ ) activities. In order to take into account this potential non-linear relationship between openness and innovative performance (Laursen and Salter, 2006; Leiponen and Helfat, 2011), we include into our regression the square terms of internal openness and external search activities.

Control Variables: We include indicators for research and development (R\&D) activities, the percentage of employees with a first and/or higher degree as measure of knowledge intensity, and information on firm age, size and related square terms.

\section{Estimation Method:}

Since the share of innovative sales is a proportion whose values are bound between zero and one hundred percent by definition, we have a double censored dependent variable and we adopt a fractional logit model (Papke and Wooldridge, 1996). We control for the potential sample selection bias by estimating a first stage probit model on the decision to engage in open innovation activities. We construct the inverse Mills ratio from the first stage selection estimation and include it as an explanatory variable in the second stage estimation. The selection equation includes size, age, R\&D expenditures, knowledge intensity and a measure of the effectiveness of IP protection at the industry level. As a robustness check, and in order to allow comparisons of our results with previous studies, we also apply Tobit analysis (Greene, 2000).

\section{RESULTS}

The results of the paper show that external knowledge flows are positively associated with innovative performance (HP 1). A unit increase in external openness is associated with a $3.6 \%$ increase in innovative sales. In line with prior research, innovative performance has an 
inverted U-shaped relation with firms' external search activities (Laursen and Salter, 2006; Leiponen and Helfat, 2011; Love et al., 2011), although only a small fraction of business service firms suffer from decreasing returns of openness.

With regard to the impact of internal openness on innovative performance (HP 2), we find that firms that are internally more open perform better than those that are not. A unit increase in internal openness enhances innovative sales by around $7 \%$. When we consider the moderating effect of internal openness on the relation between external openness and innovative performance (HP 3), contrary to expectations the result is significant and negative. This suggests a potential substitution effect between internal and external openness.

Results for hypothesis 4, which explored the relative importance of informal and formal external searches for innovative performance, shows that only informal search activities are positively associated with innovative sales. A unit increase in informal OI activities is associated with an approximately 5\% increase in innovative sales, confirming our hypothesis. When we further explore the composition of the negative interaction effect of internal and external openness on innovative performance, we find that the negative effect is driven by formal external knowledge searches. Simultaneous engagement in informal and formal external search activities (HP 5) has a negative impact on innovative performance.

Overall, business service firms seem to benefit much more from informal search activities than formal collaborative agreements and from their internal openness. When we unpack the variation of these effects across firm size classes (non-linear effects across size distributions are not picked up by the firm size indicator in the two-stage estimation procedure), we find: 1) evidence of complementarities between internal R\&D investments, internal openness and informal open innovation activities in micro-firms (less than 9 employees); positive effects of external openness on innovative performance amongst small firms (between 10 and 50 employees), with stronger positive effects for formal than informal openness and negative interaction effects between formal and informal openness; and finally 3) evidence of the strongest effect of openness on innovation for medium sized firms (more than 50 employees), with a squared term positive and significant, suggesting increasing returns to external search..

Amongst these medium-sized firms, we also find that the interaction between internal and external openness exerts a significant negative effect, whereas for smaller firms the effect is negative but not statistically significant. The effect of open innovation depends on informal activities for micro and medium-sized firms. However, for medium-sized firms this positive effect is enhanced by internal openness, suggesting a complementary relationship between internal openness and informal external search. Conversely, results for the interaction effect between internal openness and formal search is negative, which suggests a degree of attrition between formal open innovation activities and organisational arrangements that favor internal co-operation, flat hierarchies and informal management styles.

\section{CONCLUSION}

Firms differ in the way in which they facilitate internal knowledge flows and in the way in which they search for, access and use knowledge. In this paper, we investigate the performance effect of the strategic decisions regarding the mechanisms of knowledge exchange within and across organizational boundaries. Through an original survey of UK firms, we explore a particular set of firms - business services - which prior literature describes as exemplar 
developers, integrators and traders of knowledge. These characteristics make business services an ideal setting to evaluate firms' exploitation of knowledge flows.

We find that both internal and external knowledge flows are associated with firms' innovative performance. However, the results from the empirical analysis hint to a substitution effect between these two types of knowledge flows. As far as different mechanism of access to external knowledge, we find that only informal practices are positively associated with innovative performance. As observed by Hamel, Doz and Prahalad (1989, p: 136) "Many of the skills that migrate between companies are not covered in the formal terms of collaboration. Top management puts together strategic alliances and sets the legal parameters for exchange. But what actually gets traded is determined by day-to-day interactions of engineers, marketers, and product developers". Previous research points to time and cost constraints to explain firms' choice of informal over formal means of knowledge exchange (Bonte and Keilbach, 2005); these constraints may also cancel out the potential positive effect on innovative performance.

Contrary to expectations, we do not find evidence on the moderating performance effect of informal knowledge flows. On the contrary, engaging simultaneously in both informal and formal search activities seems to decrease the firm's innovative performance. Different sets of organizational skills may be needed to govern different types of knowledge flows. Finally, our in-depth analysis of size effects reveals considerable heterogeneity. The positive effect of external openness seems very much related to the firm's size with larger SMEs deriving substantially larger benefits from external knowledge flows.

This paper contributes to the theory of the knowledge-based firm by relating internal and external, and formal and informal knowledge flows with innovative performance. It highlights the effects of complementary and alternative mechanisms through which knowledge is created, absorbed, leveraged and exchanged within and across firm boundaries. The empirical contribution of the paper is an original quantitative analyses of micro-level behaviors for which there has traditionally been scarcity of data for applied research. Furthermore, the paper extends our understanding of a sector of the economy - business services - which is still underresearched relative to the manufacturing sector despite its very substantial, and increasing, contribution to economic growth in advanced economies.

The availability of panel data with additional information on organisational patterns and individual incentives may in the future provide further evidence on the causal relationship between knowledge flows, their characteristics and firm performance.

\section{END NOTES}

In our final sample, firms have on average $63 \%$ of their employees with a higher degree compared to $33 \%$ in the rest of the sample.

\section{REFERENCES and TABLES OF RESULTS ARE AVAILABLE FROM THE AUTHORS}

